\title{
Monocytes in inflammatory bowel disease: phagocytosis and intracellular killing
}

\author{
AS MEE,* M SZAWATAKOWSKI, AND DP JEWELL $\dagger$ \\ From the Academic Department of Medicine, Royal Free Hospital, London NW3 2QG, UK
}

SUMMARY The ability of peripheral blood monocytes from patients with ulcerative colitis and Crohn's disease to phagocytose and kill a standard strain of Staphyloccus aureus has been studied. Using lysostaphin, a rapidly acting muralytic enzyme, phagocytosis could be accurately differentiated from intracellular killing. When compared with normal healthy individuals and patients with gastrointestinal diseases not thought to be immunologically mediated, monocytes from patients with inflammatory bowel disease showed a statistically significant increase in the number of bacteria phagocytosed in 2 hours. There was no difference, however, between patients with Crohn's disease and those with ulcerative colitis. For all groups studied, more than $95 \%$ of ingested organisms were killed, and there was no difference between groups.

These results suggest that peripheral blood monocytes in patients with Crohn's disease and ulcerative colitis are activated. It is unlikely that the granulomata of Crohn's disease result from a defect in the microbicidal function of the monocyte/macrophage system.

The stimulus for intestinal macrophages to aggregate and form granulomata in Crohn's disease is unknown. It is known, however, that graulomata produced in response to certain bacteria, such as mycobacteria and L-forms of streptococci, are the result of macrophages being unable to degrade these organisms completely. ${ }^{1}$ It is also known that intestinal granulomata occur in chronic granulomatous disease, ${ }^{2}$ a disease in which there is impaired intracellular killing of bacteria by neutrophils and monocytes.

Since monocytes are likely to be the major source of tissue macrophages, ${ }^{3-5}$ the present study has investigated the phagocytic function and intracellular killing of peripheral blood monocytes.

\section{Methods}

PATIENTS STUDIED

Monocyte phagocytosis and intracellular killing was investigated in 15 patients with Crohn's disease and in 15 patients with ulcerative colitis and compared with that found in 28 normal healthy controls and 16 disease controls. The diagnoses of Crohn's disease and ulcerative colitis were made on standard

*Present address: The Middlesex Hospital, Mortimer Street, London W1

† Present adress: John Radcliffe Hospital, Oxford

Received for publication 28 January 1980 clinical, histological, and radiological criteria.

For the patients with Crohn's disease, disease severity was graded according to the criteria of de Dombal et al. ${ }^{6}$ while for patients with ulcerative colitis it was graded according to the criteria of Truelove and Witts. ${ }^{?}$

The disease control group consisted of patients with either peptic ulceration, chronic pancreatitis, or the irritable bowel syndrome, none of which is thought to be immunologically mediated.

The age and sex distribution is shown in the Table.

Age and sex distribution of subjects studied

\begin{tabular}{lccl}
\hline Subjects studied & No. & Sex & Mean age (range) \\
\hline Normal controls & 28 & $9 \mathrm{~F}$ & $30 \cdot 6(20-57)$ \\
& & $19 \mathrm{M}$ & \\
Disease controls & 16 & $7 \mathrm{~F}$ & $43 \cdot 3(19-68)$ \\
& & $9 \mathrm{M}$ & \\
Ulcerative colitis & 15 & $9 \mathrm{~F}$ & $37 \cdot 7(20-81)$ \\
& & $6 \mathrm{M}$ & \\
Crohn's disease & 15 & $9 \mathrm{~F}$ & $41 \cdot 3(15-77)$ \\
& & $6 \mathrm{M}$ & \\
\hline
\end{tabular}

MONOCYTE ISOLATION

A monocyte-enriched population of cells was obtained by layering heparinised whole blood over a 
Ficoll-Triosil gradient. ${ }^{8}$ After centrifugation, the interface was removed with a Pasteur pipette, and the cells were washed three times in Hanks's balanced salt solution (HBSS, Gibco Biocult, Glasgow) before being finally resuspended in Hanks's gel $(0.1 \%$ gelatin in HBSS $)$. Cells were counted using a Neubauer counting chamber, and monocytes were identified by staining for peroxidase positivity. ${ }^{9}$ The final cell suspension was then adjusted to $1 \times 10^{7}$ monocytes $/ \mathrm{ml}$. Cell viability was assessed by Trypan blue exclusion.

\section{PREPARATION OF ORGANISMS}

The Oxford strain of Staphylococcus aureus was used throughout the study. A suspension of the organism was cultured for 14 hours overnight in Hanks's gel to ensure that the bacteria were in a stationary phase of their growth curve. The bacteria were then harvested by centrifugation at $50 \mathrm{~g}$ for 5 minutes, washed three times in normal saline, and finally resuspended in Hanks's gel to a concentration of $1 \times 10^{7}$ organisms $/ \mathrm{ml}$. This was measured by assessing the turbidity of the bacterial suspension spectrophotometrically at a wavelength of $550 \mathrm{~nm}$. An optical density of $\mathbf{0 . 3}$ corresponded to approximately $1 \times 10^{7}$ bacteria $/ \mathrm{ml}$, confirmed by pour plate colony counts.

\section{DETERMINATION OF PHAGOCYTOSIS AND}

INTRACELLULAR KILLING

Phagocytosis and killing assays were performed using a modification of the original technique described by Tan et al. ${ }^{10}$ for neutrophils and by Weston et al..$^{11}$ for monocytes.

The bacteria were opsonised by the addition of $0.1 \mathrm{ml}$ of AB negative serum for a single healthy donor to $0.5 \mathrm{ml}$ of Hanks's gel containing $1 \times 10^{7}$ organisms/ml 30 minutes before the start of the experiment.

All the experiments were carried out in siliconised Leighton tubes (Trident Ltd, London).
To $0.5 \mathrm{ml}$ of the mononuclear suspension was added $250 \mathrm{U}$ of heparin. $0.5 \mathrm{ml}$ of the opsonised Staph. aureus was then added to the mononuclear suspension such that the final monocyte/bacteria ratio was approximately $1: 1$. This suspension was sonicated for 15 seconds at 45 watts to ensure that no clumping had occurred. A control tube was included with each set of experiments containing only bacteria and Hanks's gel. An $0.1 \mathrm{ml}$ aliquot was removed from each sample and serially diluted in distilled water before being plated out on Columbia blood agar (Oxoid Ltd, Basingstoke) in triplicate. The remainder of the samples were incubated on a shaking table at $60 \mathrm{rpm}$ and at $37^{\circ} \mathrm{C}$ for 2 hours. At the end of this period a further $0.1 \mathrm{ml}$ was removed and plated out as previously. A further $0.2 \mathrm{ml}$ was also removed and transferred to a $10 \mathrm{ml}$ capped plastic tube (Sterilin Ltd, Teddington) containing $50 \mu \mathrm{g}$ of filtered lysostaphin (Schwartz Mann, supplied by Beckton and Dickinson Co Ltd, Wembley) in $1 \mathrm{ml}$ HBSS.

This was incubated for 20 minutes at $37^{\circ} \mathrm{C}$ and the lysostaphin was then neutralised with $0.1 \mathrm{ml}$ of $2.5 \%$ trypsin (Novo Industria, Denmark). A further $\mathbf{0} \cdot 1 \mathrm{ml}$ was again removed from this suspension and diluted before being plated out. This count represented the number of viable intracellular bacteria present at the end of the experiment. Tan et al. ${ }^{10}$ have shown that $99.9 \%$ of extracellular bacteria are killed by this method. This was confirmed by plating out undiluted samples from the control tube which yielded no growth, thus confirming the antistaphylococcal effect of the lysostaphin.

The methodology, counts, and method of calculation are shown diagrammatically in Figures 1 and 2.

STATISTICS AND ANALYSIS

The results obtained for each group were compared using a one-way analysis of variance.

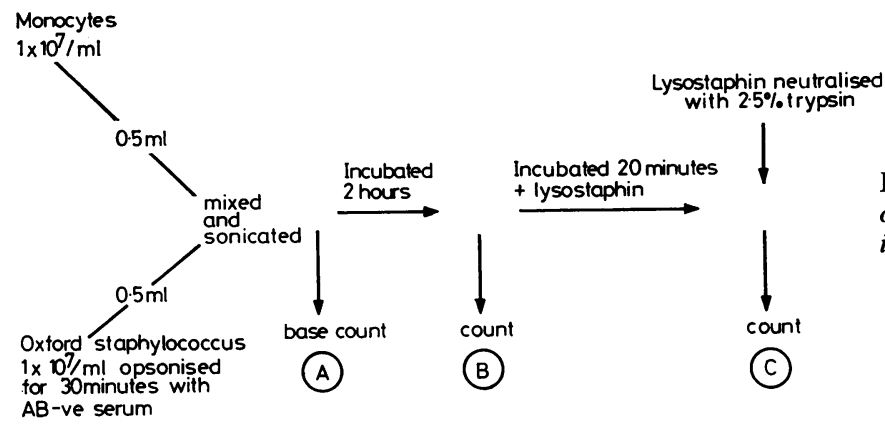

Fig. 1 Diagrammatic representation of method of assaying monocyte phagocytosis and intracellular killing of Staph. aureus. 


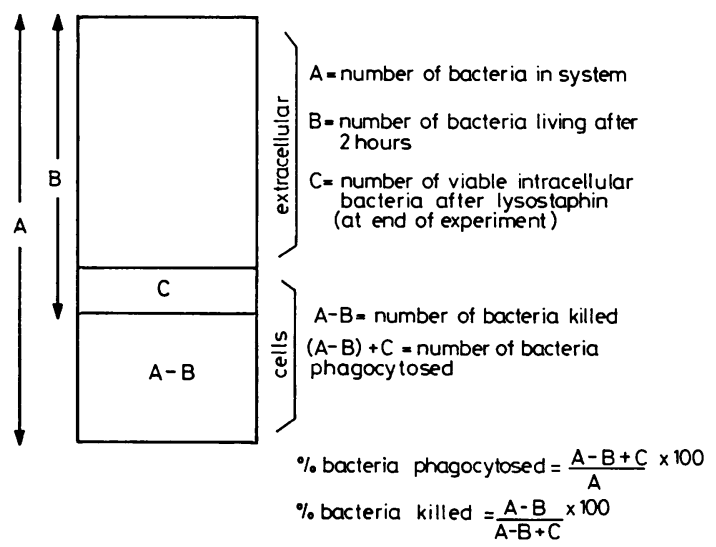

Fig. 2 Method of calculating percentage of bacteria phagocytosed and killed by monocytes.

\section{Results}

\section{PHAGOCYTOSIS}

The mean percentage ( \pm SEM) of bacteria phagocytosed in 2 hours by the monocytes of patients with Crohn's disease was $53.8( \pm 5.2) \%$ and by the monocytes of patients with ulcerative colitis $57 \cdot 3$ $( \pm 4 \cdot 1) \%$. These percentages were significantly higher than the mean percentage of $39.9( \pm 2.6) \%$ bacteria ingested by the monocytes of the normal control group and $41.8( \pm 5.4) \%$ bacteria ingested by the monocytes of the disease control group (normals $v$ Crohn's disease, $\mathrm{P}<0.02$; normals $v$ ulcerative colitis, $P<0.001$ ). There was no significant difference between normal controls and disease controls, or between Crohn's disease and ulcerative colitis. These results are shown in Figure 3.

When analysed with respect to disease activity, there was no significant difference in the percentage of bacteria ingested by the monocytes of patients with either active Crohn's disease $(n=7)$ or ulcerative colitis $(n=8)$ when compared with those with inactive disease (Crohn's disease, $n=8$; ulcerative colitis, $n=7$ ). The numbers of patients in these groups are, however, too small for meaningful statistical analysis. There did not appear to be any relation between the percentage of bacteria phagocytosed and the length of history, extent of disease, or drug therapy in patients with either Crohn's disease or ulcerative colitis.

\section{INTRACELLULAR KILLING}

The mean ( \pm SEM) percentage of ingested bacteria killed by the monocytes of patients with Crohn's disease at 2 hours 20 minutes was $96.5( \pm 1 \cdot 1) \%$ and by the monocytes of patients with ulcerative colitis $97 \cdot 7( \pm 0 \cdot 7) \%$.

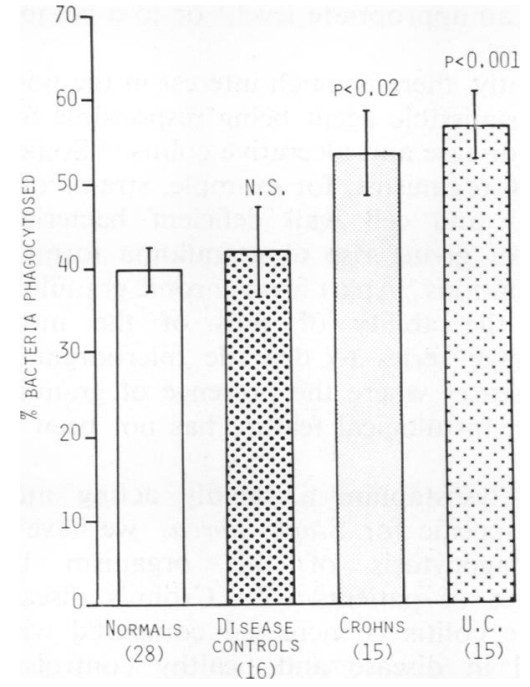

Fig. 3 Percentage of bacteria phagocytosed by patients with Crohn's disease and with ulcerative colitis, and disease controls and normal controls.

These percentages are not significantly different from the figures of $97 \cdot 8( \pm 0 \cdot 3) \%$ ingested bacteria killed by the monocytes of normal healthy controls or $96.9( \pm 0.6) \%$ ingested bacteria killed by the monocytes of the disease control group. These results are shown in Figure 4.

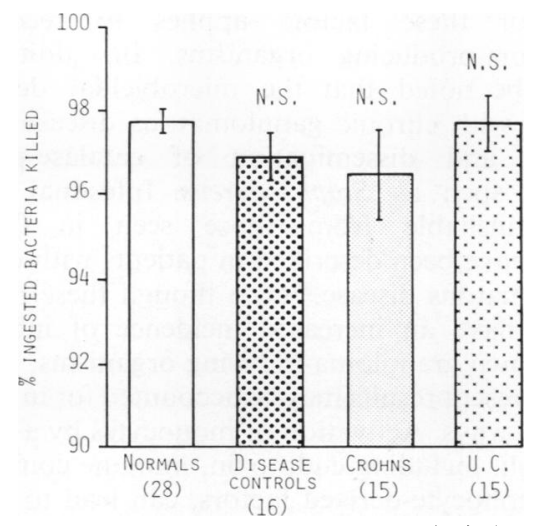

Fig. 4 Percentage of ingested bacteria killed in patients with Crohn's disease and with ulcerative colitis, and disease controls and normal controls.

\section{Discussion}

Granuloma formation may be due to the nature of the inciting agent, ${ }^{12}$ to an inability of the cells of the monocyte/macrophage series to degrade the inciting 
agent to an appropriate level, ${ }^{1}$ or to a combination of the two.

Currently, there is much interest in the possibility of a transmissible agent being responsible for both Crohn's disease and ulcerative colitis. ${ }^{13}$ Some of the candidate organisms, for example, strains of mycobacteria $^{14}$ and cell wall deficient bacteria, ${ }^{15}$ are capable of giving rise to granuloma formation in other situations. ${ }^{1}$ Apart from chronic granulomatous disease, the ability of cells of the monocyte/ macrophage series to degrade microorganisms in those diseases where the presence of granuloma is a distinct histological feature has not been studied in man.

Using lysostaphin, a rapidly acting muralytic enzyme specific for Staph. aureus, we have shown that phagocytosis of this organism by the monocytes of patients with Crohn's disease and ulcerative colitis is increased compared with that observed in disease and healthy controls. Once phagocytosed, however, the organisms are killed by the monocytes of the patients as effectively as in the control groups.

The use of Staph. aureus is not ideal since it is not known to produce granulomas, and the mechanisms of intracellular degradation of this organism are different from that of facultative and obligate intracellular parasites. However, the organism does have several advantages. Lysostaphin can be used to ensure extracellular killing, the results are reproducible, and the organism is easily cultured. None of these factors applies to recognised granuloma-producing organisms. In addition, it should be noted that the microbicidal defect in patients with chronic ganulomatous disease allows survival and dissemination of catalase-positive bacteria such as Staph. aureus. Intestinal lesions indistinguishable from those seen in Crohn's disease have been described in patients with chronic granulomatous disease, ${ }^{2}$ even though these patients do not have an increased incidence of infections with known granuloma-inducing organisms.

The present results may be accounted for in several different ways. Activation of monocytes by a variety of stimuli, including endotoxin, immune complexes, and lymphocyte-derived factors, can lead to a nonspecific increase in phagocytosis. ${ }^{1617}$ Many of these activating factors are known to occur in patients with inflammatory bowel disease, including immune complexes ${ }^{18}$ and endotoxin. ${ }^{19}$ Products of activated T lymphocytes may also be important since cellmediated responses to colonic bacterial antigens have been described in patients with both Crohn's disease and ulcerative colitis. ${ }^{20-22}$ The ingestion of microorganisms themselves may also act as a stimulus to monocyte/macrophage activation, re- sulting in enhanced phagocytic activity against either similar or other organisms. ${ }^{23}$

Opsonisation with immunoglobulin and/or complement is required for the attachment of most microorganisms to the surface of phagocytic cells. ${ }^{24}$ This attachment is facilitated by the presence of IgG and $\mathrm{C} 3$ receptors on the surface of the monocyte/ macrophage. ${ }^{25}$ It is known that the monocytes of patients with Crohn's disease have both increased IgG receptor and $\mathrm{C} 3$ receptor activity. ${ }^{26}$

Ward ${ }^{27}$ has proposed that a defect in the ability of the cells of the monocyte/macrophage series to inactivate ingested organisms is responsible for the histological lesions seen in Crohn's disease. The suggestion was that ingestion but non-degradation of certain organisms may act as a continual stimulus for the secretion of tissue-damaging lysosomal enzymes. Indeed, certain organisms such as mycobacteria, brucella, and streptococcal L-forms, which are known to produce granulomas, are less completely degraded by macrophages than non granuloma-producing organisms. ${ }^{1}$ While our results do not negate this hypothesis for granulomaproducing organisms, they do show that monocyte phagocytic activity for Staph. aureus is enhanced and that microbicidal activity for the same organism is normal in patients with inflammatory bowel disease. The enhanced phagocytic activity is further evidence that monocytes are circulating in these patients in an activated state. ${ }^{28}$

ASM was supported by the Stanley Johnson Trust.

\section{References}

${ }^{1}$ Spector WG, Reichold N, Ryan GB. Degradation of granuloma-inducing micro-organisms by macrophages. J Pathol 1970;101:339-54.

2 Ament ME, Ochs HD. Gastrointestinal manifestations of chronic granulomatous disease. $N$ Engl J Med 1973;288: 382-7.

${ }^{3}$ Volkman A, Gowans JL. The origin of macrophages from bone marrow in the rat. Br J Exp Pathol 1965;46:62-70.

4 Spector WG, Walters MN-I, Willoughby DA. The origin of the mononuclear cells in inflammatory exudates induced by fibrinogen. J Pathol Bacteriol 1965;90:181-92.

${ }^{5}$ van Furth R. Origin and kinetics of monocytes and macrophages. Semin Haematol 1970;7:125-41.

${ }^{6}$ de Dombal FT, Burton IL, Clamp SE, Goligher JC. Short term course and prognosis of Crohn's disease. Gut 1974; $15: 435-43$.

7 Truelove SC, Witts LJ. Cortisone in ulcerative colitis: Final report on a therapeutic trial. $\mathrm{Br} M e d \mathrm{~J}$ 1955;2: 1041-8.

${ }^{8}$ Böyum A. Isolation of mononuclear cells and granulocytes from human blood. Scand J Clin Lab Invest 1968;21: 77-89.

${ }^{9}$ Druguet M, Pepys MB. Enumeration of lymphocyte populations in whole peripheral blood with alkaline phosphatase-labelled reagents: A method for routine clinical use. Clin Exp Immunol 1977;29:162-7. 
10 Tan JS, Watanakunokorn C, Phair JP. A modified assay of neutrophil function: Use of lysostaphin to differentiate defective phagocytosis from impaired intracellular killing. J Lab Clin Med 1971 ;78:316-22.

11 Weston WL, Dustin RD, Hecht SK. Quantitated assays of human monocyte-macrophage function. J Immunol Methods 1975;8:213-22.

12 Thayer WR. The immunopathology of intestinal granulomatous disease. In: Frontiers of Gastrointestinal Research $1975 ; 1: 74-124$.

13 Cave DR. Is Crohn's disease a transmissible condition? In Twelfth Symposium on Advanced Medicine 1976:287-97. Edited by DK Peters, Pitman Medical.

${ }^{14}$ Burnham WR, Lennard Jones JE, Stanford JL, Bird RG. Mycobacteria as possible cause of inflammatory bowel disease. Lancet 1978;2:683-96.

15 Parent K, Mitchell P. Cell Wall-defective variants of Pseudomonas-like (Group Va) bacteria in Crohn's disease. Gastroenterology 1978;75:368-72.

16 Page RC, Davies P, Allison AC. (1974). Participation of mononuclear phagocytes in chronic inflammatory diseases. J Reticuloendothel Soc 1974;15:413-38.

17 Territo MC, Cline MJ. Mononulear phagocyte proliferation, maturation and function. Clin Haematol 1975;4:685-703.

${ }^{18}$ Hodgson HJF, Potter BJ, Jewell DP. Immune complexes in ulcerative colitis and Crohn's disease. Clin Exp Immunol 1977;29:187-96.

19 Bowen GE, Kirsner JB. Positive epinephrine test for 'circulating endotoxin' in inflammatory disease of the intestine. Am J Clin Pathol 1965;44:642-7.

${ }^{20}$ Bull DM, Ignaczak TF. Enterobacterial common antigeninduced lymphocyte reactivity in inflammatory bowel disease. Gastroenterology 1973;64:43-50.

${ }^{21}$ Bartnik W, Swarbrick ET, Williams C. A study of peripheral leucocyte migration in agarose medium in inflammatory bowel disease. Gut 1974;15:294-300.

22 Eckhardt R, Heimisch M, Meyer zum Büschenfelde KH. Cellular immune reactions against common antigen, small intestine and colon antigen in patients with Crohn's disease, ulcerative colitis and cirrhosis of the liver. Scand J Gastroenterol 1976;11:49-54.

${ }^{23}$ Schnyder J, Baggiolini M. Role of phagocytosis in the activation of macrophages. J Exp Med 1978;148:1449-57.

${ }^{24}$ Holland P, Holland NH, Cohn ZA. The selective inhibition of macrophage phagocytic receptors by anti-membrane antibodies. J Exp Med 1972;135:458-75.

${ }^{25}$ Huber H, Fudenberg HH. Receptor sites of human monocytes for IgG. Int Arch Allergy 1968;34:18-31.

${ }^{26}$ Schmidt ME, Douglas SD. Monocyte IgG receptor activity, dynamics and modulation-normal individuals and patients with granulomatous diseases. J Lab Clin Med 1977;89:332-9.

27 Ward M. The pathogenesis of Crohn's disease. Lancet $1977 ; 2: 903-5$.

${ }^{28}$ Mee AS, Jewell DP. Monocytes in inflammatory bowel disease: Monocyte and serum lysosomal enzyme activity. Clin Sci 1980;58:295-300.

Requests for reprints to: Dr DP Jewell, John Radcliffe Hospital, Headington, Oxford. 